\title{
Computer Simulation of PMSM Motor with Five Phase Inverter Control using Signal Processing Techniques
}

\author{
Khalaf S. Gaeid ${ }^{1}$, Mshari Aead Asker ${ }^{2}$, Nada N. Tawfeeq ${ }^{3}$, Salam Razooky Mahdi ${ }^{4}$ \\ ${ }^{1,3,4}$ Department of Electrical Engineering Department, Tikrit University, Iraq \\ ${ }^{2}$ Department of Computer Science Department, Tikrit University, Iraq
}

\begin{tabular}{l}
\hline \hline Article Info \\
\hline Article history: \\
Received May 19, 2018 \\
Revised Jul 20, 2018 \\
Accepted Jul 26, 2018 \\
\hline
\end{tabular}

\section{Keyword:}

5 phase inverter

Fault tolerant control

PMSM

Vector control

Wavelet

\begin{abstract}
The signal processing techniques and computer simulation play an important role in the fault diagnosis and tolerance of all types of machines in the first step of design. Permanent magnet synchronous motor (PMSM) and five phase inverter with sine wave pulse width modulation (SPWM) strategy is developed. The PMSM speed is controlled by vector control. In this work, a fault tolerant control (FTC) system in the PMSM using wavelet switching is introduced. The feature extraction property of wavelet analysis used the error as obtained by the wavelet de-noised signal as input to the mechanism unit to decide the healthy system. The diagnosis algorithm, which depends on both wavelet and vector control to generate PWM as current based manage any parameter variation. An open-end phase PMSM has a larger range of speed regulation than normal PMSM. Simulation results confirm the validity and effectiveness of the switching strategy.
\end{abstract}

Copyright @ 2018 Institute of Advanced Engineering and Science. All rights reserved.

Corresponding Author:

Khalaf S. Gaeid,

Departement of Electrical Engineering Department,

Tikrit University, Iraq.

Email: gaeidkhalaf@gmail.com

\section{INTRODUCTION}

Nowadays, the energy and maintenance saving in the large-scale AC motor drive systems are very crucial requirement to modify machines to electric-powered for improve their performance. Multi-phase inverter drive is used for driving a large-scale motor as well as the other types of motors [1]. In the past few years, the conventional IMs has been replaced by PMSMs in spite their cost is relatively higher. PMSMs are popular in industry with advanced performance due to the high precision torque, lower maintenance cost such as in electric traction, steel mill ,military weapons, elevators, electric machines, servo systems, and hybrid vehicle [2].Multi-winding motors can be used with all types of control techniques either closed loop or openloop control such as direct torque control (DTC), volt to frequency (V/f) control and vector control particularly with PMSM motors [3]. In the literature many research works on multiphase motors fault conditions such as in [4]. Signal processing techniques is used to detect the faults of PMSM control system [5]. In [6], current control is imposed to minimize the torque ripple in the five-phase segment motor when one phase get opened. Feedback current control, uses a sum of current of inverter phases to calculate the information to control the system faults with single or multi controllers. Fault tolerant studies presented different topologies to have sufficient operation of any given faulty system and increasing the reliability [7].Control schemes of open windings (OW) PMSM and inverters to optimize the motor's working range and efficiency is introduced in [8]. A fault tolerant control strategy for a single open phase fault (OPF) in a threephase PMSM improved in [9]. A wavelet can be defined as a waveform of limited period that has zero average value [10]. The fault diagnosis task is to locate and identify the fault in the closed loop system model meanwhile FTC which is to obtain satisfactory operation and recover from the specific faults. Neural network combination with adaptive filter as one kind of the signal processing in the fault diagnosis sensorless control 
scheme is introduced in [11]. Digital signal processing with highly advanced chip to design a PMSM digital controller introduced in [12].

The sensors, electronic components of machine drives and the environment faults such as wires and connectors are the main types of system faults. Wavelet vector control PMSM motor drives analysis and feature extraction in FTC and signal processing combination with different degree of open circuit failure introduced in [13]. In high voltage high power energy control, the Multilevel inverter uses as an important alternative technology due to its less blocking voltage requirement of semiconductor power devices, THD and voltage insulation [14]. Power semiconductor is the most weakness devices in industrial applications [15]. PMSMs faults can be divided into two main parts, electrical faults and mechanical faults. Open and short stator winding short turn faults are common in electrical part and it is caused by the combination of various stresses acting on the stator, such as thermal, electrical, mechanical, and environmental stresses [16].

The of multiphase machines development specially five-phase, offers improved performance to realize sinusoidal input current and unity power factor [17]. The main topologies of multilevel inverters are diode clamped or neutral point clamped multilevel inverter, DC link voltage stable adopt inverter one approach the multilevel inverter three-level neutral point clamped (3LNPC) capacitor clamped or flying capacitor multilevel inverter and cascaded H-bridge multilevel inverter [18]. Sensorless vector control strategy for the PMSM drive operating at low switching frequency with programmed PWM methods introduced in [19].

The multilevel inverter with discrete wavelet based fault diagnosis is explained in [20], [21]. PMSM motor multiple faults Identifying in with vector control method based on the wavelet and complex wavelet feature enhancements used in [22]. The singular value vectors is obtained using the output voltage waveforms of the faulty inverter through a decomposing of discrete orthogonal wavelet transform [23].

The safety, costs and condition monitoring equipment is the main considerations in any fault diagnosis [24]. The voltage current topology is used to diagnose the open circuit fault in the NPC three levels converter [25]. Wavelet packet transform (WPT) to diagnose a faulty inverter, sliding mode observer, expert systems, fuzzy logic and artificial intelligence proposed in [26]. Discrete wavelet transform (DWT) second harmonic component analysis used in the voltage source inverter circuit and stator fault diagnosis [27]. The multilevel converters offers a wide range of FTC options due to the inherent redundancies and modularity of such a topology [28].

The main contribution of this paper is, increase the reliability of the PMSM closed loop control system, introduce new FTWT combined with vector control strategy through smooth switching technique.

The structure of this paper follows: PMSM motor mathematical model in Section 2, vector control techniques is given in Section 3, in Section 4, the characteristic of the SPWM converter is obtained, the proposed signal processing techniques is given in Section 5, comparative study in Section 6. Finally, Section 7 gives a conclusions about this study.

\section{PMSM MOTOR MATHEMATICAL MODEL}

Interest in Multi-phase motor drives get a highly interest during last decade. PMSM are becoming attractive in many industrial applications due to their smooth output response, reliability, higher efficiency, lower torque pulsations at higher frequencies and power density. The main components of the electrical drives can be shown as in the Figure 1.

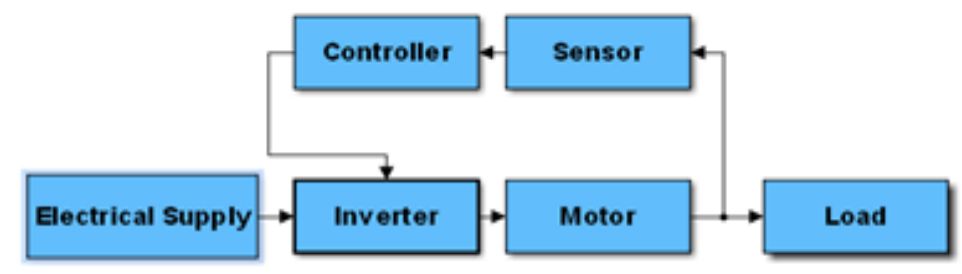

Figure 1. Main components of electrical drives

In the implementation of the five-phase PMSM machine, the stator windings are connected in wye to an internal neutral point. The five-phase machine has a sinusoidal back EMF waveform and round rotor. Mathematical model of PMSM describe in this paper is based on following assumptions [29]. 
a. No core saturation and

b. The winding leakage inductance can be ignored

c. Pure sine wave in air gap and the higher harmonic can be negligible.

The stator voltage equation can be written as;

$$
\mathrm{v}_{\mathrm{s}}=i_{s} \mathrm{R}_{\mathrm{s}}+\frac{\mathrm{d} \lambda_{\mathrm{s}}}{\mathrm{dt}}
$$

The air gap flux linkages

$$
\begin{aligned}
& \lambda_{\mathrm{s}}=\lambda_{\mathrm{ss}}+\lambda_{\mathrm{m}} \\
& \lambda_{\mathrm{ss}}=\mathrm{L}_{\mathrm{ss}} \mathrm{i}_{\mathrm{s}}
\end{aligned}
$$

Lss, $\lambda \mathrm{m}$, Rs, is, $\lambda \mathrm{s}$ is the stator inductance matrix, the flux linkage matrix ,stator resistance matrix, current matrix, flux linkages matrix respectively. The stator currents are:

$$
\left[\mathrm{i}_{\mathrm{s}}\right]=\left[\begin{array}{lllll}
\mathrm{i}_{\mathrm{as}} & \mathrm{i}_{\mathrm{bs}} & \mathrm{i}_{\mathrm{cs}} & \mathrm{i}_{\mathrm{ds}} & \mathrm{i}_{\mathrm{es}}
\end{array}\right]^{T}
$$

The self and mutual inductances are assumed to have same value for all the phases as in (5).

$$
\left[\mathrm{i}_{\mathrm{s}}\right]=\left[\begin{array}{lllll}
\mathrm{i}_{\mathrm{as}} & \mathrm{i}_{\mathrm{bs}} & \mathrm{i}_{\mathrm{cs}} & \mathrm{i}_{\mathrm{ds}} & \mathrm{i}_{\mathrm{es}}
\end{array}\right]^{T}
$$

The self and mutual inductances are assumed to have same value for all the phases as in (5).

$$
\begin{aligned}
& \mathrm{L}_{\mathrm{aa}}=\mathrm{L}_{\mathrm{bb}}=\mathrm{L}_{\mathrm{cc}}=\mathrm{L}_{\mathrm{dd}}=L_{e e} \\
& \mathrm{~L}_{\mathrm{ab}}=\mathrm{L}_{\mathrm{bc}}=\mathrm{L}_{\mathrm{cd}}=\mathrm{L}_{\mathrm{de}}
\end{aligned}
$$

The phase variables of the PMSM motor are transformed into a reference frame. This just simplify the PMSM model. The transformation matrix for this system is given by the following matrix [14].

$$
\begin{aligned}
& A=\sqrt{2 / 5} * \\
& {\left[\begin{array}{ccccc}
\cos \theta_{\mathrm{s}} & \cos \left(\theta_{\mathrm{s}}-\alpha\right) & \cos \left(\theta_{\mathrm{s}}-2 \alpha\right) & \cos \left(\theta_{\mathrm{s}}+2 \alpha\right) & \cos \left(\theta_{\mathrm{s}}+\alpha\right) \\
-\sin \theta_{\mathrm{s}} & -\sin \left(\theta_{\mathrm{s}}-\alpha\right) & -\sin \left(\theta_{\mathrm{s}}-2 \alpha\right) & -\sin \left(\theta_{\mathrm{s}}+2 \alpha\right) & -\sin \left(\theta_{\mathrm{s}}+\alpha\right) \\
1 & \cos 2 \alpha & \cos 4 \alpha & \cos 4 \alpha & \cos 2 \alpha \\
0 & \sin 2 \alpha & \sin 4 \alpha & -\sin 4 \alpha & -\sin 2 \alpha \\
\frac{1}{\sqrt{2}} & \frac{1}{\sqrt{2}} & \frac{1}{\sqrt{2}} & \frac{1}{\sqrt{2}} & \frac{1}{\sqrt{2}}
\end{array}\right]}
\end{aligned}
$$

By applying this transformation to the stator voltages and flux presented in (1) and (2) and taking the values of $(\theta s=0 \& \alpha=2 \pi / 5)$ in this transformation, the following equations are obtained:

$$
\begin{aligned}
& \mathrm{v}_{\mathrm{ds}}=R_{s} i_{d s}-\omega \lambda_{\mathrm{qs}}+p \lambda_{d s} \\
& \mathrm{v}_{\mathrm{qs}}=R_{s} i_{q s}-\omega \lambda_{\mathrm{ds}}+p \lambda_{q s} \\
& \lambda_{\mathrm{ds}}=\left(\mathrm{L}_{\mathrm{ls}}+L_{m}\right) \mathrm{i}_{\mathrm{ds}}+\lambda_{m} \\
& \lambda_{\mathrm{ds}}=\left(\mathrm{L}_{\mathrm{ls}}+L_{m}\right) \mathrm{i}_{\mathrm{qs}}
\end{aligned}
$$


Substituting the values from Equations (7)-(10), the following matrix is obtained:

$A=\sqrt{2 / 5} \sqrt{a^{2}+b^{2}}$

$\left[\begin{array}{ccccc}\mathrm{R}_{s}+L_{q} P & \omega L_{d} & 0 & 0 & 0 \\ -\omega L_{q} & \mathrm{R}_{s}+L_{d} P & 0 & 0 & 0 \\ 1 & 0 & \mathrm{R}_{s}+L_{l s} & 0 & 0 \\ 0 & 0 & 0 & \mathrm{R}_{s}+L_{l s} & 0 \\ 0 & 0 & 0 & 0 & \mathrm{R}_{s}+L_{l s}\end{array}\right]\left[\begin{array}{l}i_{d} \\ i_{q} \\ i_{x} \\ i_{y} \\ i_{0}\end{array}\right]$

$+\left[\begin{array}{l}\omega \lambda_{m} \\ 0 \\ 0 \\ 0 \\ 0\end{array}\right]$

The output torque $\mathrm{T}$ can be expressed as:

$\mathrm{T}=\frac{5}{2} \frac{P}{2}\left[\lambda_{\mathrm{m}} i_{q s}\right]$

$T=\frac{5 \mathrm{P}}{4}\left[\lambda_{d s} \mathrm{i}_{\mathrm{qs}}-\lambda_{\mathrm{qs}} i_{d s}\right]$

Simulink implementation of PMSM electrical part can be shown as in Figure 2.

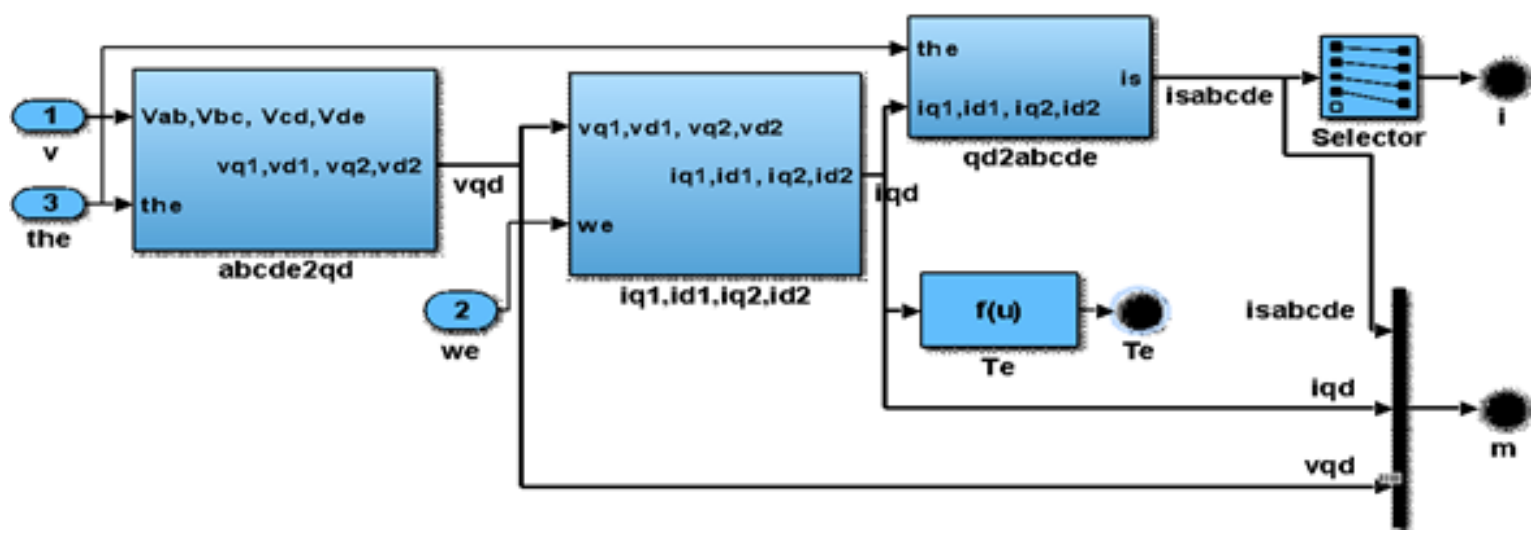

Figure 2. Electrical part of the PMSM

The mechanical part of the PMSM can be drived from the torque Te which is a function of the stator fluxes and currents. As in the electrical part, the mechanical part of the PMSM can be shown as in Figure 3.

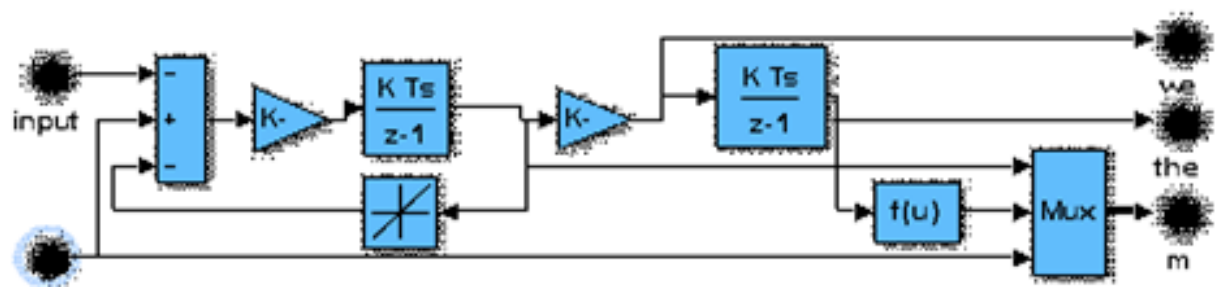

Figure 3. Mechanical part of the PMSM 
The ploynimail faulty and healthy modes of the control system are implemented by Identification Matlab toolbox.

\section{VECTOR CONTROL TECHNIQUE}

Vector control in industrial applications are very popular. The basic principles of vector control, with the help of the phasor diagram is shown in Figure 4 [30].In order to control the output torque of the machines, the vector control isolates linear and nonlinear PMSM flux and torque undividauly and operates as a separately excited DC machine. The three phase voltage and current are converted to two phase wire d and $\mathrm{q}$ axis. Synchronization with the $\mathrm{d}-\mathrm{q}$ frame rotating rotor magnetic flux vectors [31].

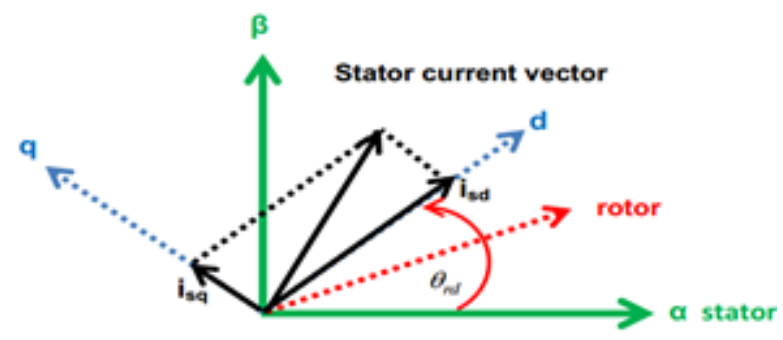

Figure 4. Stationary reference of vector control

This making PMSM to work as a high-performance during all the operating area.The Simulink unit of vector control to produce control gates for the five phase inverter can be shown in Figure 5.

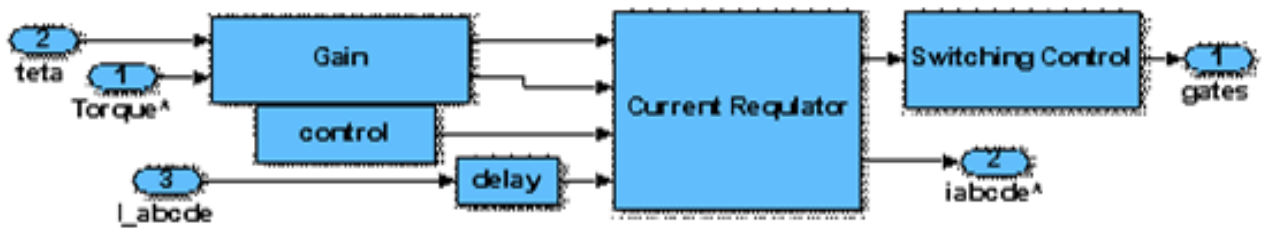

Figure 5. Vector control simulink implementation

The decoupled control of torque and flux, the higher efficiency for each operation point in a wide speed range, and the better dynamic behavior are the main advantages of the vector control.

\section{SPWM INVERTER}

The three-phase conventional sine wave PWM is easier in implementation compare to any other topology [35], produces a lower amount of heat during the period of switching, consumes less power and operate with higher frequencies. In this paper five phase ten switch inverters are used in five phase voltage source inverter (VSI) [32]. Many researches have been investigating VSI and CSI types of faults inverters. The output waveform and reduce harmonic distortion is very important to improve the inverters. In multilevel inverters, the cost, size, complexity of control scheme and reliability are depends on the number of devices needed [33]. Multilevel inverters with the number of switches needed for each configuration can be shown in Table 1.

Table 1. Multilevel Inverters with the Number Needed

\begin{tabular}{cccc}
\hline & Diode clamp & Flying capacitor & cascaded \\
\hline Main switching devices & $(\mathrm{N}-1) * 2$ & $(\mathrm{~N}-1)^{*} 2$ & $(\mathrm{~N}-1)^{*} 2$ \\
Main diodes & $(\mathrm{N}-1)^{* 2}$ & $(\mathrm{~N}-1)^{*} 2$ & $(\mathrm{~N}-1)^{* 2}$ \\
Clamping diodes & $(\mathrm{N}-1)^{*}(\mathrm{~N}-2)$ & 0 & 0 \\
DC bus capacitors & $(\mathrm{N}-1)$ & $(\mathrm{N}-1)$ & $(\mathrm{N}-1) / 2$ \\
Balancing capacitors & 0 & {$[(\mathrm{~N}-1) *(\mathrm{~N}-2)] / 2$} & 0 \\
\hline
\end{tabular}

Computer Simulation of PMSM Motor with Five Phase Inverter Control using Signal ... (Khalaf S. Gaeid) 
The Space Vector Pulse Width Modulation (SVPWM) makes the motor drives more reliable in terms of system parameters. This method generates less Total Harmonic Distortion (THD) in the output voltages and currents, which provides more efficient use of the DC supply voltage $(90.7 \%)$ in comparison to sinusoidal PWM techniques [34]. Though it has higher utilization and efficiency, the application of SVPWM is limited in five-phase system, as it needs to control 32 switching states. The sinusoidal pulse width modulation (SPWM) and its control circuit shown in Figure 6.

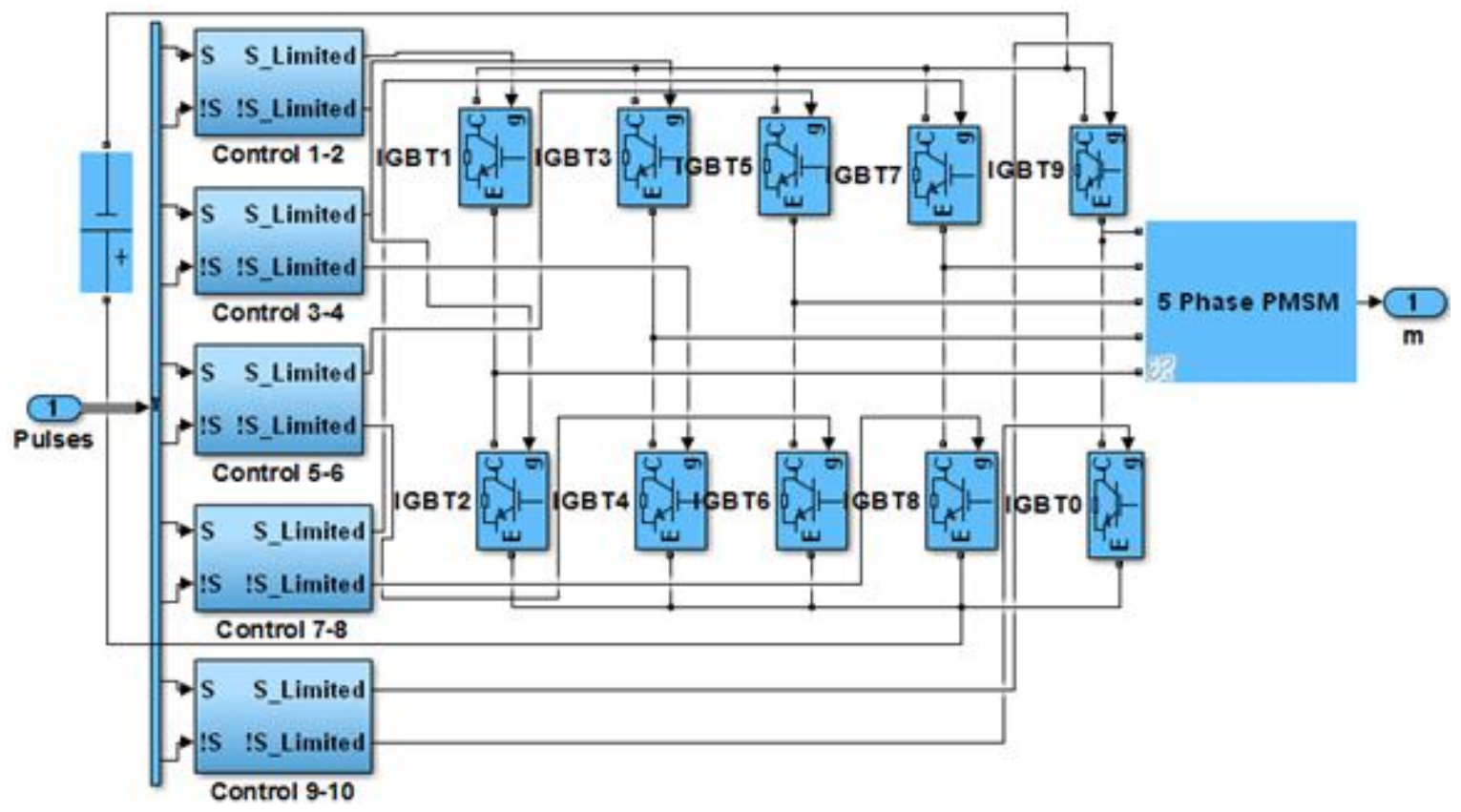

Figure 6. SPWM inverter complete circuit

In [36], [37], the efficiency of SPWM was measured and estimated to prove a lower DC link voltage utilization. In this study, a five phase PMSM motor is being considered to extend the operational range of SPWM for a five-phase inverter and maintain a sufficient output response during the occurrence of faults.

\section{SIGNAL PROCESSING TECHNIQUES}

Signal processing and intelligent systems have gained importance in many tasks, such as fault location and estimation, load estimations, reactive power compensation, the risk of blackouts. HVDC systems for many application with a fast, accurate and reliable protection algorithms have a major interest[38].The wavelet used signal processing system objects such as the dyadic analysis filter bank and dyadic synthesis filter bank to de-noise a noisy signal using soft thresholds.

The Discrete Wavelet Transform (DWT) decompose the signals at numerous scales of time and frequency resolution. DLPF with impulse response begins with DWT, pass the discrete original noisy signal signal, wavelet coefficients, output response through filter with impulse response.

The residue signal displays the error between the original and de-noised signal and can be used for the switching mechanism between the healthy and faulty PMSM control system. Several signal processing mathematical techniques such as small signal state space averaging, Fourier technique, time domain methods, short time Fourier transform (STFT), is used to analyse the performance of switching power converters. The finite energy is the most powerful tool in signal time-wavelet frequency characteristics.

The admissibility and regularity condition are important properties of the wavelet as can be expressed in the following formula [39].

$$
\int \frac{|\psi(\omega)|^{2}}{|\omega|} d \omega<+\infty
$$


$\psi(\omega)$ is used to perform the signal with Fourier transform using the wavelet function. The losing function of the information can checked in (15).

$$
|\psi(\omega)|^{2}=0
$$

The wavelet can be used in many applications such as a compression signal processing, image analysis, statistics, nonlinear dynamic process modelling. It also has wide range of applications in electrical engineering fields such as measurement of harmonics in power lines under non-steady state conditions, disturbance evaluation, de-noising in signal processing, fast transient analysis like lightening induced disturbances, fault identification \& diagnostics in electrical machine, electronic issues of power harmonic analysis of switching power supply noise.

The detection of the any faulty signal can be either through switching measurement or output waveform analysis [40].

The wavelet transform by using a 3-level wavelet $\mathrm{db} 10$ depending on a positive level, signals of PMSM motor are analysed with the above type of wavelet.

Simulink implementation of the noise reconstruction and noise reduction wavelet to generate the failures symptom can be shown in Figure 7 and Figure 8 respectively.

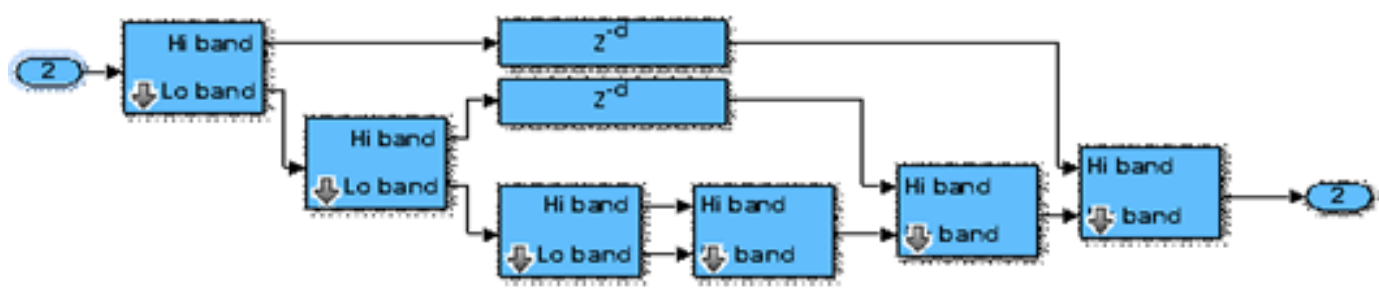

Figure 7. Noise reconstruction wavelet unit

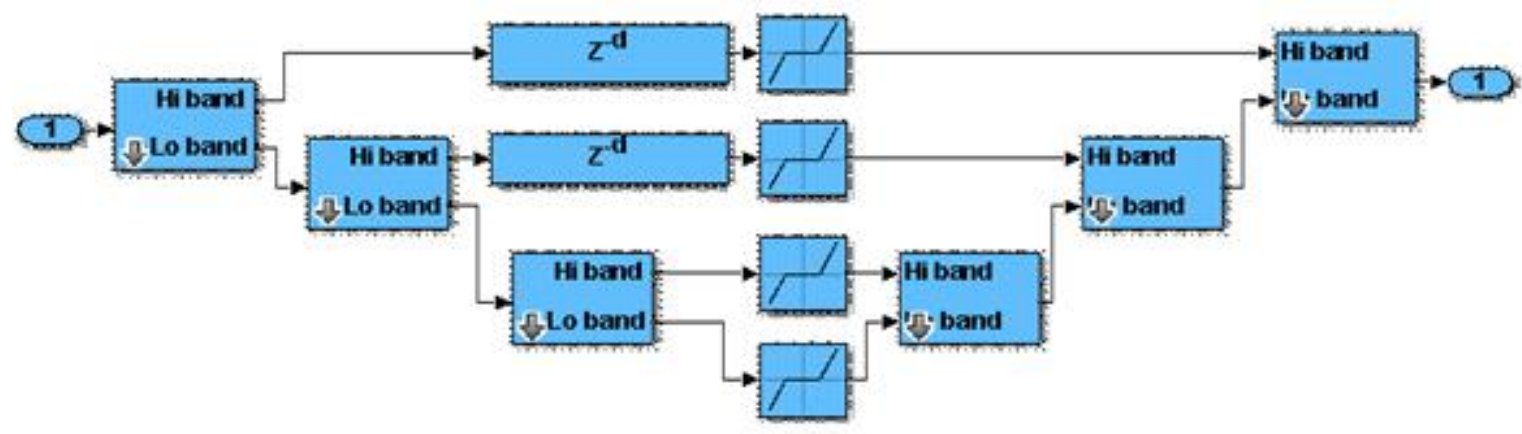

Figure 8. Noise reduction wavelet unit

The discrete wavelet transforms is used for the feature extraction system. The discretized mother wavelet function can be defined as:

$$
\psi_{m, n}(t)=a_{0}^{-m / 2} \psi\left(\frac{t-n b_{0} a_{0}^{m}}{a_{0}{ }^{m}}\right)
$$

The corresponding DWT can be defined:

$$
\mathrm{DWT}_{\psi} \mathrm{x}(\mathrm{m}, \mathrm{n})=\int_{-\infty}^{\infty}\left(x(t) \psi^{*}{ }_{m, n}(t) d t\right)
$$


Where, a0 and $\mathrm{b} 0$ are the fixed constants with: $\mathrm{a} 0>1, \mathrm{~b} 0>0,(\mathrm{~m}, \mathrm{n} \in \mathrm{N})$. Here $\mathrm{N}$ is the set of positive integers [36].

During a fault condition inverter multiple level current signal is known from the DWT fault value output time and frequency in time and frequency. The dependence of the flux and torque of the motor speed is used as a basis to detect faults.

$\mathrm{d} 3$ detailed decomposition is the information about the current state of the stator can be derived from the frequency and high pass filter.

The best wavelet decomposition levels can be obtained according to the following criteria:

$$
W_{\text {decomp }}=\frac{\log \left(f_{s} / f\right)}{\log (2)} \pm 1
$$

Where $f$ s is the sampling frequency and $f$ is the nominal frequency.

The wavelet high pass and low pass filters coefficient in both decompostion and recontructed stages are illustrated as in Figure 9.

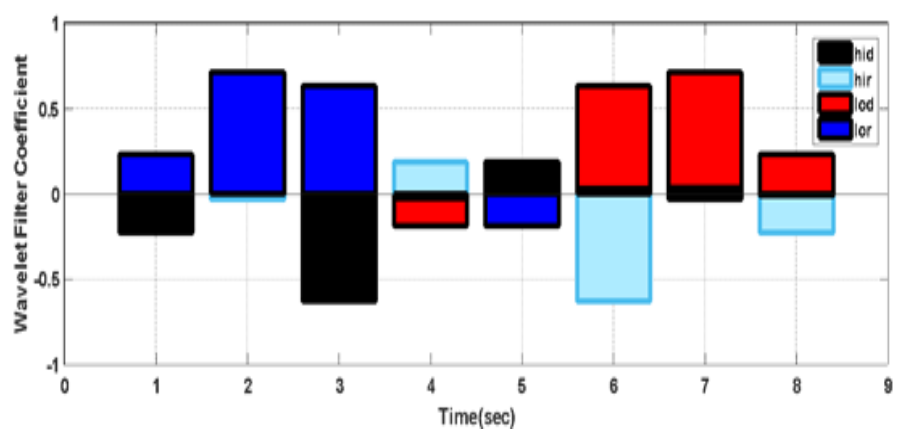

Figure 9. Wavelet Coefficient of high and low pass filters

\section{COMPARTIVE STUDY}

MATLAB/ Simulink is used to model all the individual units of the PMSM closed control system. A five-phase motor rated $4.4 \mathrm{~kW}$ fed by a SPWM inverter shown in Figure 10. The SPWM inverter outputs goes through controlled voltage source blocks before being applied to the PMSM block's stator windings. The load torque applied to machine's shaft is fixed to 12 N.m.

Two control loops are used, the first one is the inner loop to regulate the motor's stator currents. This is faster than the second speed control loop by ten times.

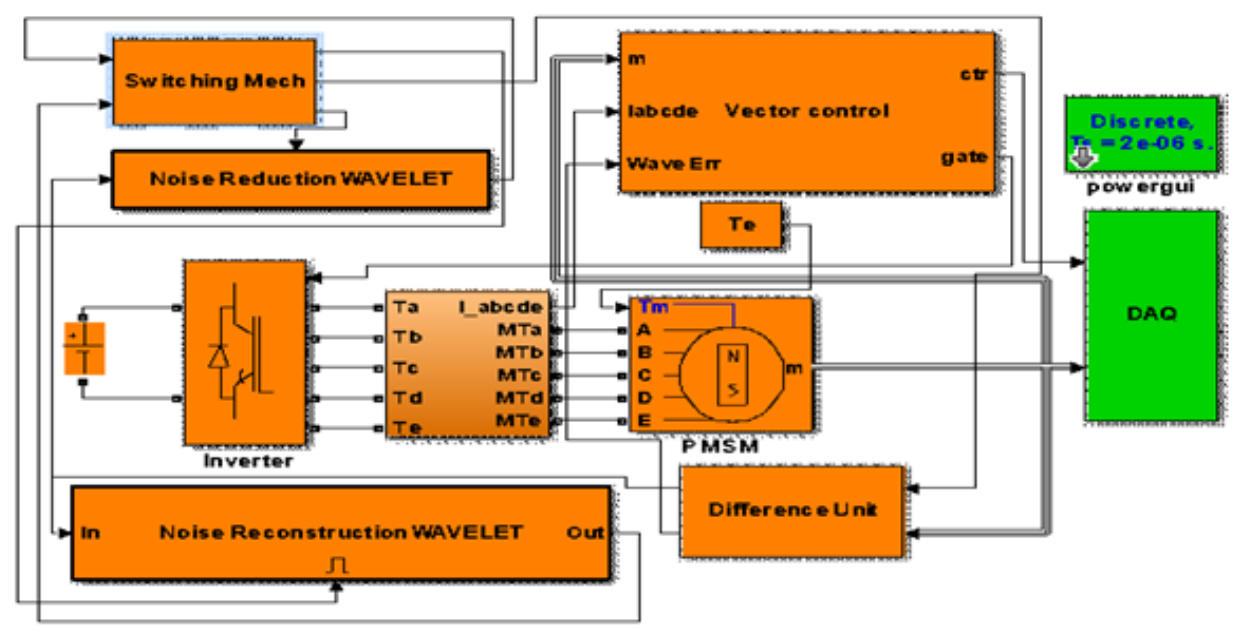

Figure 10. Simulink proposed circuit 
The proposed comparative study is based on the following procedure:

\subsection{Healthy case}

The five-phase PMSM control performances in healthy conditions are shown in Figure 11 to Figure 13, respectively illustrating the PMSM currents, the rotor speed and motor torque. Smooth operation in all the three figures proves the healthy operation.

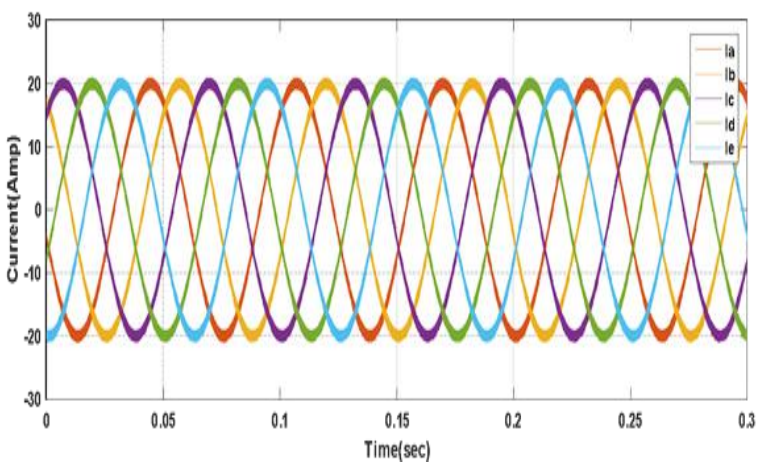

Figure 11. PMSM healthy current

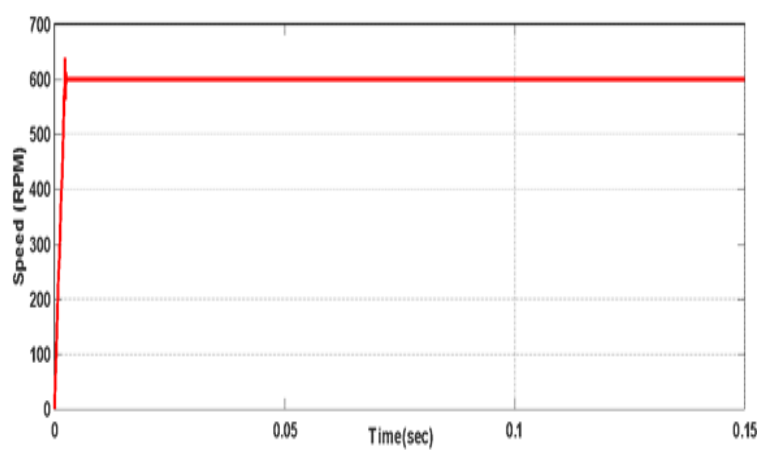

Figure 12. PMSM healthy speed

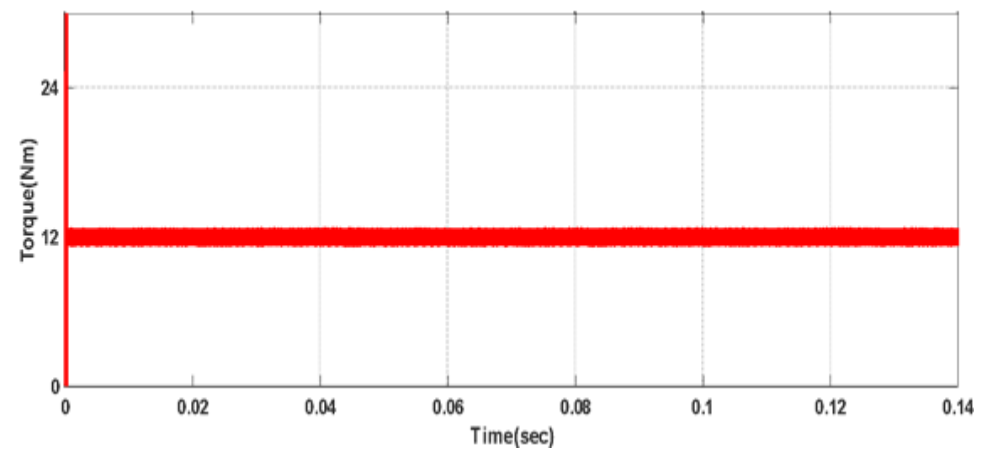

Figure 13. PMSM healthy Torque

\subsection{Faulty Case without Proposed Algorithm}

The operation of machine is tested under faulty condition. The open fault of one phase is introduced at $0.7 \mathrm{sec}$. Initially speed was set to $600 \mathrm{rpm}$ until the occurrence of the fault. Reduction of operation speed is acceptable until the second fault at $3 \mathrm{sec}$. the speed decreased to $200 \mathrm{rpm}$ with large ripple as can be shown in Figure 14.

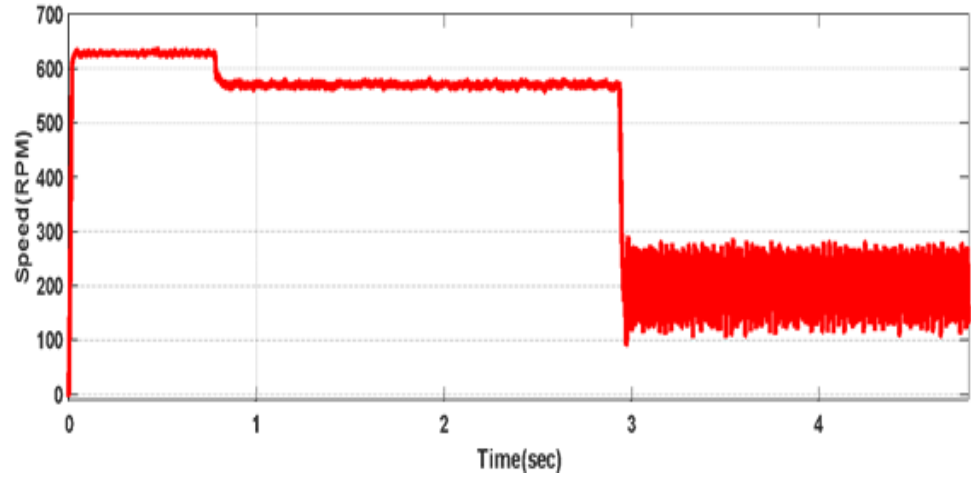

Figure 14. Actual speed PMSM faulty 
The correspondent current waveform can be shown in Figure 15. We can see a large spikes of current during non-steady state modes.

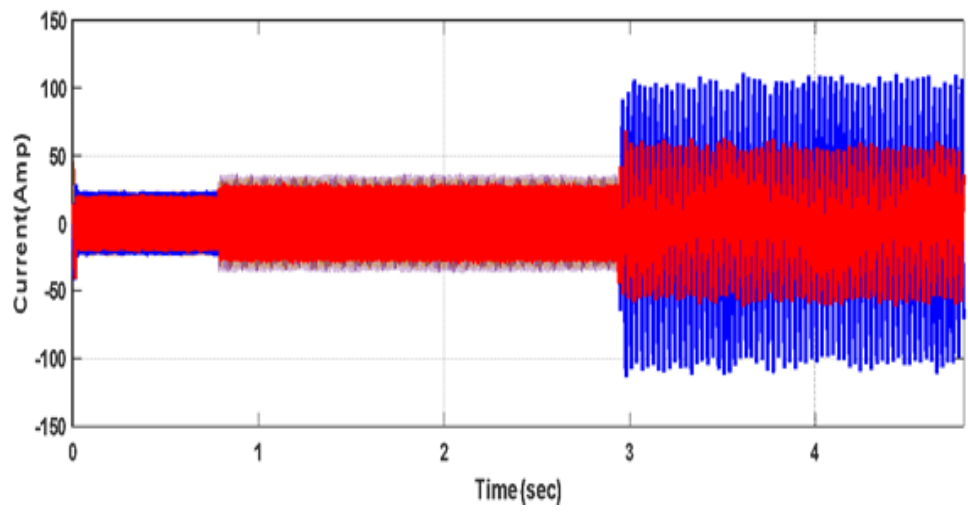

Figure 15. PMSM current under the system variation parameter

\subsection{Faulty case with proposed algorithm}

The proposed algorithm is tested with lose one and two phases at a time. Figure 16 illustrate Iabcde current waveform which is non-sinusoidal in the beginning due to open fault at observed that waveform amplitude is decreased during less load value.

Variation of amplitude indicates that for more torque more current is needed. In this situation, the currents in other phases get distorted which reduces the output torque. Figure 17 shows the torque at twophase open faults and reference torque is changed between $(12,-12) \mathrm{Nm}$.

It was observed that the torque at single phase open fault improved. The output torque can be maximized under fault condition by modifying the magnitudes and phases in the remaining phase currents.

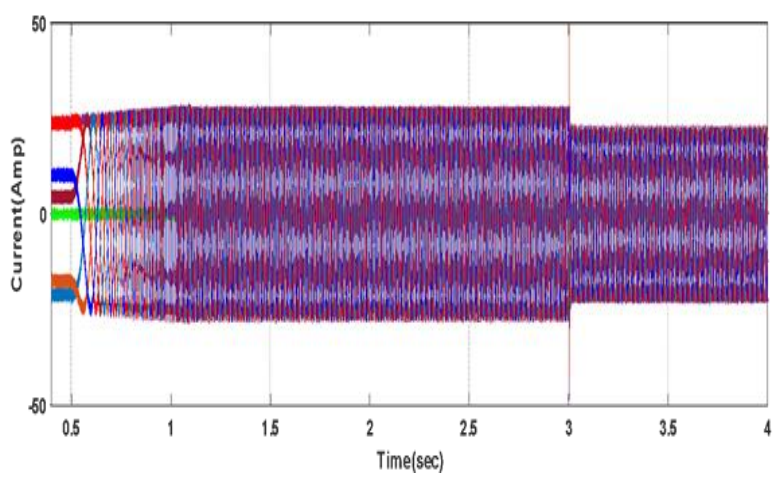

Figure 16. Reference and actual speed

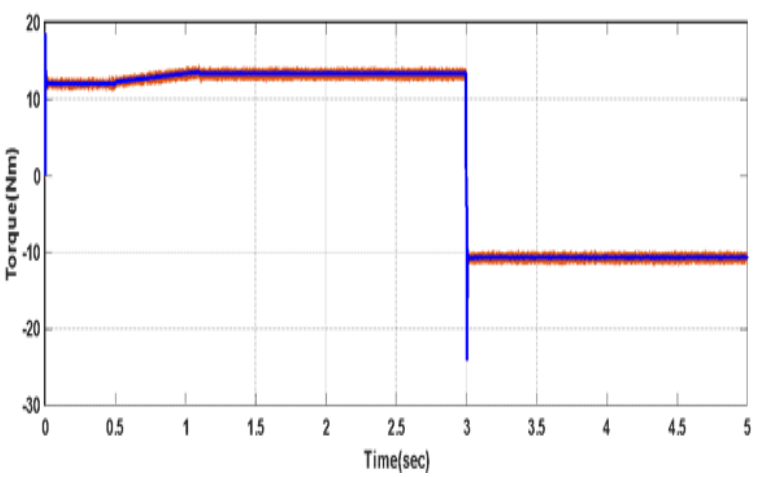

Figure 17. Torque actual and reference

The speed is gradually increased during the fault periods (0.5 and 3) sec and high torque needed until stability obtained as can be shown in Figure 18.

Apart from these large spikes, torque is kept constant at input load value of $12 \mathrm{Nm}$ in steady states and flow the reference directly. Indeed, the torque remains quiet smooth.

The dq component of current is shown in Figure 19, its d- component is almost remain at zero as commanded throughout the graph.

But some distortion can be seen in the non-stable regions due to sudden introduce of a fault at $3 \mathrm{sec}$.

This algorithm can be activated in the system based on the type of fault. Wavelet decomposition of db10 with three levels during smooth switching operation between fault to healthy mode can be shown in Figure 20.

To get the gain margin and phase margin, the bode plot of the model process is shown in Figure 21. 
The values of gain margin and phase margin which are below shows the stability of the system consideration due to their positive signs.

$[\mathrm{GM}=+2.2108 \mathrm{e}+08, \mathrm{PM}=+93.9196]$

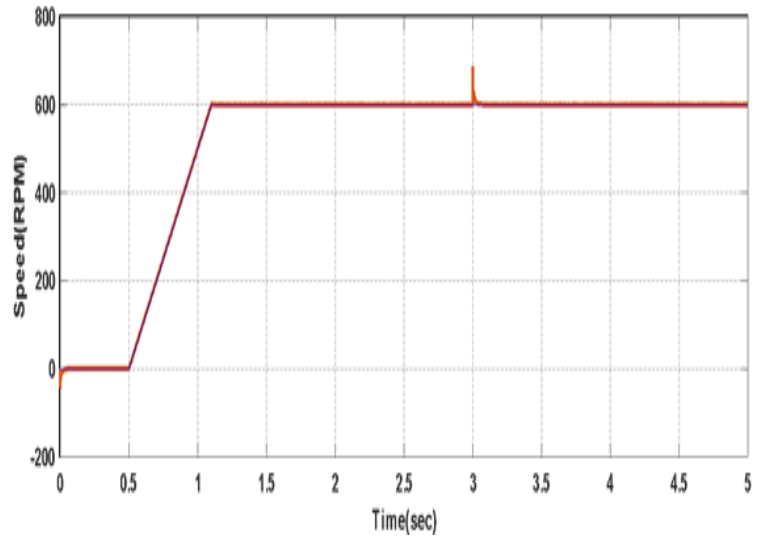

Figure 18. Reference and actual speed

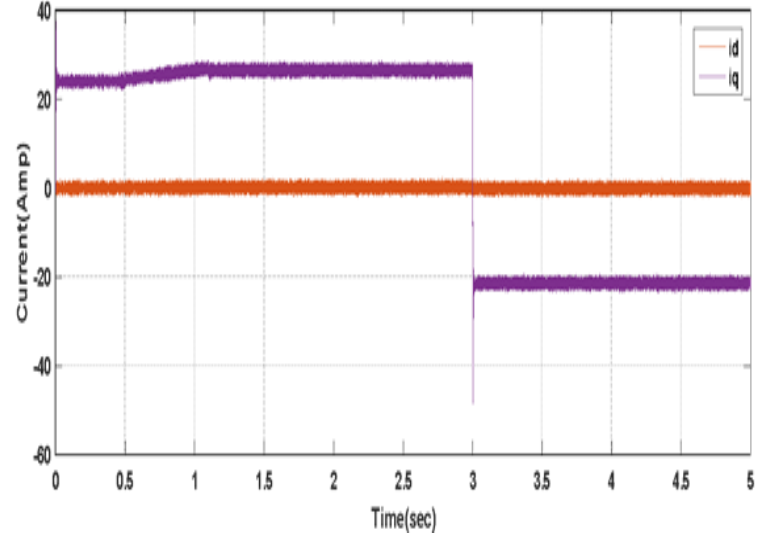

Figure 19. id and iq current components during proposed method

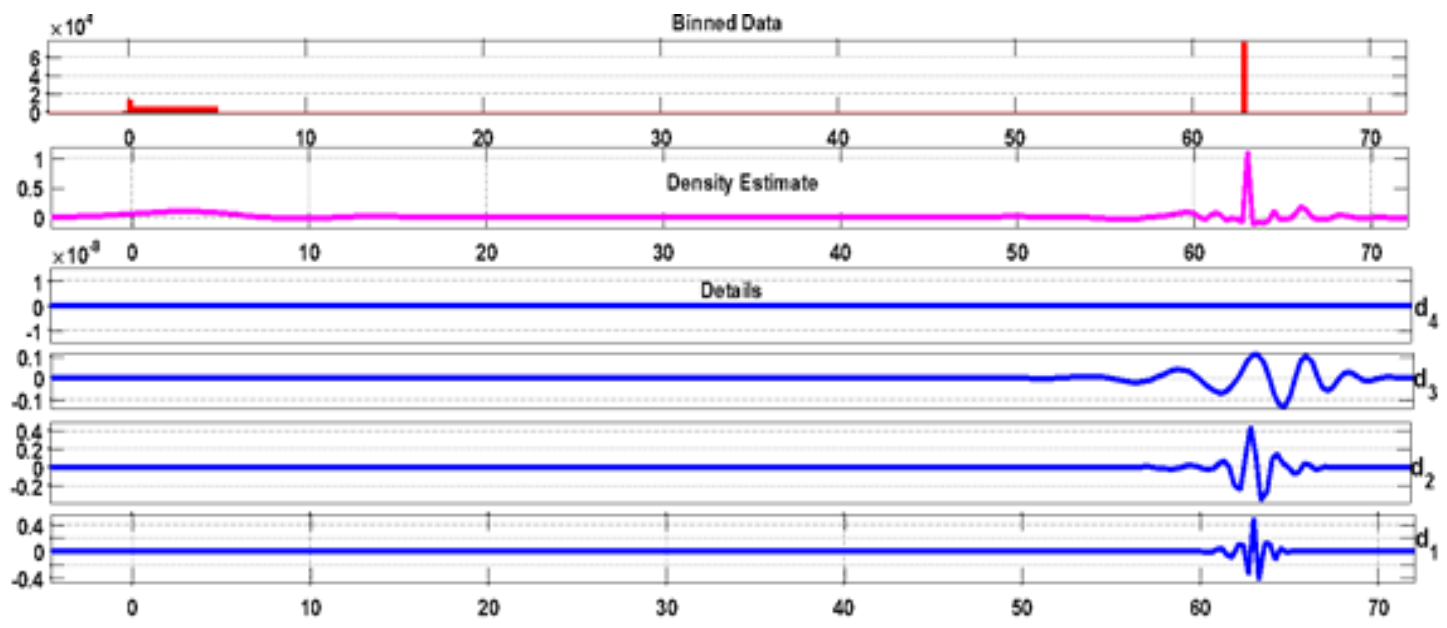

Figure 20. Wavelet decomposition during switching operation

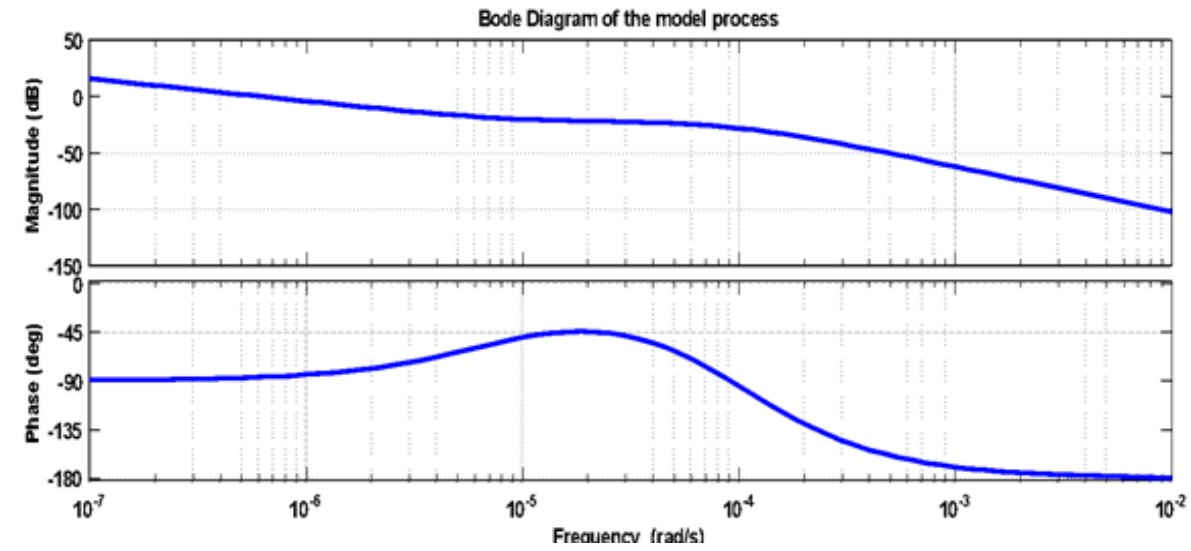

Figure 21. Bode plot of the Final process model 

toolbox.

The final process healthy model transfer function can be found using Matlab/Simulink identification

$$
G(s)=\frac{6.4571 \mathrm{e}-07(1-125851.9673 s)}{s(1+0.001069 s)(1+10000 s)^{2}}
$$

\section{CONCLUSION}

Signal processing fast and low cost new algorithm for open phase FTC wavelet based in SPWM feeding five phase PMSM was proposed in this paper. The measurement of the output inverter currents that are already available for a closed-loop control of the electric drive is only needed.

The achievements of a reconfiguration for sufficient of PMSM motor operation, and avoid the propagation of the fault in the other parts are the most important finding in this paper.

The new wavelet based FTC approach is derived from the operating characteristics of the five-phase PMSM under one and two open phase faults. The switching between the vector control and the wavelet show the validity and the feasibility of the proposed method

\section{REFERENCES}

[1] A. Satake, et al., "Design of Coupling Cancellation Control for a Double-winding PMSM", IEEJ Journal of Industry Applications, vol. 6 no. 1 pp. 29-35, 2017.

[2] P. Pillay and R. Krishnan, "Modeling, Simulation, and Analysis of Permanent-Magnet Motor Drives, Part I: The Permanent-Magnet Synchronous Motor Drive", IEEE Transactions on Industry Applications, vol. 25, no. 2, pp. 265-27, 1989.

[3] A.Guglielmi, et al., "Sensorless Direct Torque Control for PM-Assisted Synchronous Motors with Injection HighFrequency Signal Into Stator Flux Reference Frame", IEEE International Symposium on Sensorless Control for Electrical Drives (SLED), Italy. pp. 139-144, 2017.

[4] F. Baudart, et al., "Control Strategy with Minimal Controller Reconfiguration of Fault Tolerant Polyphase PMSM drives under Open Circuit Fault of One Phase", Electrical Machines (ICEM), 2010 XIX International Conference on., pp. 1-6, 2010.

[5] Z. Jun, et al., "PMSM Control System based on Digital Signal Processor", Journal of Networks, vol. 8, no. 4, pp. 924-931, 2013.

[6] H. Kesraoui, et al., "Five-Phase Permanent Magnetic Synchronous Motor Fed by Fault Tolerant Five Phase Voltage Source Inverter", International Journal of Electrical and Computer Engineering (IJECE), vol. 6, no. 5, pp. 1994-2004, 2016.

[7] T. J. Dos, et al., "Dual-Multiphase Motor Drives for Fault- Tolerant Applications: Power Electronic Structures and Control Strategies", IEEE Transactions on Power Electronics, vol. 33, no. 1, pp. 572-580, 2018.

[8] L.Chu, et al., "Research on Control Strategies of an Open-End Winding Permanent Magnet Synchronous Driving Motor (OW-PMSM)-Equipped Dual Inverter with a Switchable Winding Mode for Electric Vehicles", Energies, vol. 10, no. 5, 2017.

[9] C. J. Meirrinho et al., "Fault Tolerant Control for Permanent Magnet Synchronous Motor", IEEE International Electric Machines and Drives Conference (IEMDC), 2017.

[10] S.Benelghali, et al., "Performance Comparison of Three-and Five-Phase Permanent Magnet Generators for Marine Current Turbine Applications Under Open-Circuit Faults", International Conference on Power Engineering, Energy and Electrical Drives (POWERENG), IEEE, pp. 1-6, 2011.

[11] L. Tian, et al., "Sensorless Control of Interior Permanent Magnet Synchronous Motor in Low-Speed Region using Novel Adaptive Filter", Energies, vol. 9, pp. 1-18, 2016.

[12] L. Li, et al., "DSP based Digital Control System Implementation of Permanent Magnet Synchronous Motor Control and Decision,"Conference (CCDC), 2014.

[13] L. Parsa, and H. A. Toliyat, "Sensorless direct torque control of Five-PhaseInterior Permanent-Magnet Motor Drives", IEEE transactions on industry applications, vol. 43, no. 4, pp. 952-959, 2007.

[14] A. Nigam and S. Siddiqui, "Modeling and Simulation of Five Phase Permanent Magnet Synchronous Motor", VSRD-TNTJ, vol. 1, no. 2, pp. 78-86, 2010.

[15] B. Wang, et al., "Review of Power Semiconductor Device Reliability for Power Converters", CPSS Transactions on Power Electronics and Applications, vol. 2, no. 2, pp. 101-117, 2017.

[16] C. Chuang, et al., "Diagnosis Method of Stator winding Faults in PMSMs based on SOM Neural Networks", Energy Procedia, vol. 105, pp. 2295-2301, 2017.

[17] M. Masoud," Fully Controlled 5-phase, 10-pulse, Line Commutated Rectifier”, Alexandria Engineering Journal, vol. 54, no. 4, pp. 1091-1104, 2015.

[18] F. Amin, et al., "Modelling and Simulation of Field Oriented Control based Permanent Magnet Synchronous Motor Drive System", Indonesian Journal of Electrical Engineering and Computer Science, vol. 6, no. 2, pp. 387-395, 2017.

Int J Elec \& Comp Eng, Vol. 8, No. 5, October 2018 : 3697 - 3710 
[19] P. Kshirsagar and R. Krishnan, "Sensorless Position Control of PMSM Operating at low switching Fequency for high Fficiency Climate Control Systems", Electric Machines and Drives Conference (IEMDC), IEEE International, 2017

[20] G. Renukadevi, and K. Rajambal, "Field programmable gate array implementation of space-vector pulse-width modulation technique for five-phase voltage source inverter", Power Electronics, IET Journals \& Magazines, vol. 7, no.2, pp. 376-389, 2014.

[21] K, O. Ojo and M. Abreham, "Carrierbased PWM Scheme for a three-level Diode-clamped five-phase Voltage Source Inverter Ensuring Capacitor Voltage Balancing", Applied Power Electronics Conference and Exposition (APEC), 2011 Twenty-Sixth Annual IEEE, pp. 1194-1201, 2011.

[22] W. Sun, et al., "An Intelligent Gear Fault Diagnosis Methodology Using a Complex Wavelet Enhanced Convolutional Neural Network", Materials, vol. 10, no. 7, 2017.

[23] Z. Hu, et al., "Fault Classification Method for Inverter based on Hybrid Support Vector Machines and Wavelet Analysis", International Journal of Control, Automation and Systems, vol. 9, p. 797, 2011.

[24] W. Lingmei, et al., "State Monitoring and Fault Diagnosis of Wind Turbines", chapter in Advances in Energy Systems Engineering (Spring ed), pp. 803-822, 2017.

[25] P. Sanoop and V. Chellappan, "Seven Level Inverter Topologies: A Comparative Study", International Journal of Innovative Research in Electrical, Electronics, Instrumentation and Control Engineering, vol. 3, no. 1, pp. 148-163, 2016.

[26] X. Yang, et al., "Fault Diagnosis of Power Electronic Circuits based on Wavelet Packet Decomposition and LibSVM”, Revista de la Facultad de Ingeniería U.C.V., vol. 31, no. 7, pp. 215-225, 2016.

[27] S. Huang, et al., "Overview of Condition Monitoring and Operation Control of Electric Power Conversion Systems in Direct-drive wind turbines under faults Front", Mechnical Engineering, vol. 12, no. 3, pp. 281-302, 2017.

[28] A. Ghazanfari, "Control, Modulation, and Protection Strategies for Modular Multilevel Converters in Smart AC and DC Grids Applications", A thesis of Doctor of Philosophy in Energy Systems. University of Alberta, 2017.

[29] E. Sulaiman, et al., "Modelling and Simulation of Field Oriented Control based Permanent Magnet Synchronous Motor Drive System", Indonesian Journal of Electrical Engineering and Computer Science, vol. 6, no. 2, pp. 387-395, 2017.

[30] K. S. Gaeid, et al., "Indirect Vector Control of a Variable Frequency Induction Motor Drive (VCIMD) Instrumentation, Communications", Information Technology, and Biomedical, 2009.

[31] K. S. Gaeid, et al., "Sensor and Sensorless Fault Tolerant Control for Induction Motors Using a Wavelet Index", Sensors, vol. 12, no. 4, pp. 4031-4050, 2012.

[32] M.A Inayathullaah and R. Anita, "Simulation of Five Phase Voltage Source Inverter with Different Excitation for Star Connected Load", International Journal of Engineering and Technology (IJET), vol. 6, no. 3, pp. $1573-1580,2014$.

[33] M. Karimi, et al., "A Developed single-phase Cascaded Multilevel Inverter with Reduced Number of Circuit Devices", International Journal of Ambient Energy, vol. 38, no. 4, pp. 1-9, 2017.

[34] A. Iqbal, et al., "Generalized Sinusoidal PWM with Harmonic Injection for Multi-Phase VSIs", in IEEE Power Electronics Specialists Conference (PESC), 2006.

[35] A. K. M. Arafat, "Fault Tolerant Control of a Five-Phase Permanant Magnet Assisted Synchronous Reluctance Motor", Master of Science thesis. University of Akron, 2015.

[36] M. P. Kazmierkowski and L. Malesani, "Current Control Techniques for Three-Phase Voltage-Source PWM Converters: A Survey", IEEE Transactions on Industrial Electronics, vol. 45, no. 5, pp. 691-703, 1998.

[37] K Zhou and D Wang, "Relationship between Space-Vector Modulation and Three-Phase Carrier-Based PWM: A Comprehensive Analysis”, IEEE Transactions on Industrial Electronics, vol. 49, no. 1, pp. 186-196, 2002.

[38] F. Unal and S. Ekic, "A Fault Location Technique for HVDC Transmission Lines using Extreme,125-130, Learning Machines", IEEE ICSG, 2017.

[39] K. S. Gaeid and H W Ping, "Wavelet Fault Diagnosis and Tolerant of Induction Motor: A Review", International Journal of the Physical Sciences, vol. 6, no. 3, pp. 358-376, 2011.

[40] K. S. Gaied, et al., "Nonlinear Compensation Empyoing Matrix Inverter with DTC Controller", International Journal of Electrical and Computer Engineering (IJECE), vol. 7, no. 1, pp. 107-124, 2017.

\section{BIOGRAPHIES OF AUTHORS}

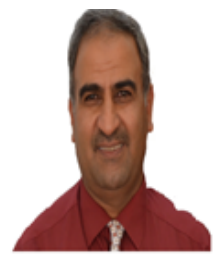

Khalaf S Gaeid (M'12) was born in Iraq, in 1969. He received the B.Eng. and M.Sc. degrees from the University of Technology, Baghdad, Iraq, in 1993 and 2003, respectively, and the Ph.D. degree in 2012 from the University of Malaya, Kuala Lumpur, Malaysia, all in electrical engineering, specializing in control systems. Since 2005, he has been a Lecturer at Tikrit University, where he is associate professor with Electrical Engineering Dpartment. His research interests include faulttolerant control, control of induction machines, applications of wavelet theory to electrical signals, the fault diagnosis of induction machines. He has published more than 40 papers in the area of control. 


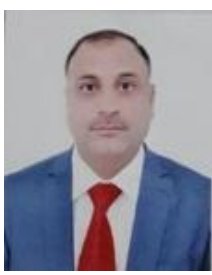

Mshari Aead Asker received the B.Sc. degree in Computer Science from university of Mosul in 2003, the D.Eng. degree in Computer engineer from university of Aleppo in 2006, the M.Eng. degree in Computer engineer from university of Aleppo in 2008,and the Ph.D. degree in Computer engineer from university of Aleppo in 2015.He is the head of the computer science department at the Faculty of Computer Science and Mathematics at the University of Tikrit. His research interest include digital signal processing, security, and computer network.

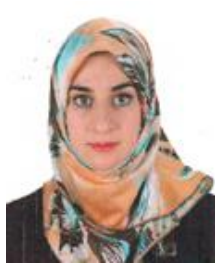

Nada Nasih Tawfeeq received her BSc. in Electrical Engineering from Tikrit University in 2009 and MSc. from Mosul University with communication specialization in 2014. Her research area interest includes antenna, digital signal processing and wireless communication system design. Currently she is working as an Assistant Instructor in university of Tikrit/College of Engineering/Electrical department.

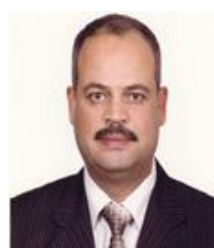

Salam Razooky Mahdi received the B.Sc Mathematic science from Baghdad University Baghdad-Iraq in 1990. 1998-1999 Iraqi Commission for Computers and Informatics/ Informatics Institute for Post Graduate Studies. Higher Diploma of Computer science.2002-2005 Iraqi Commission for Computers and Informatics/Informatics Institute for Post Graduate Studies where he Completed the Msc in Computer science. Ph.D in Electrical \& Electronic in 2015 from Aleppo University, Aleppo-Syria. His research interest include digital signal processing, security, and computer network. 